Short Communication

\title{
Electrochemical Investigation of the Solid-State Reference Electrode Based on Activate Carbon for Corrosion Monitoring of Reinforced Concrete Structures
}

\author{
Wei He ${ }^{*}$, Rong He
}

School of Civil Engineering and Communication, North China University of Water Resources and Electric Power, Zhengzhou 450045, P.R. China

*E-mail: weihe_2009@yahoo.com

doi: $10.20964 / 2016.09 .35$

Received: 5 June 2016 / Accepted: 7 July 2016 / Published: 7 August 2016

The electrochemical activated carbon is a kind of application for assembling the solid-state reference electrode. The electrochemical characters of the reference electrode are temperature response, potential stability and the impact of classic ions, which are surveyed at length. The performance of polarization is confirmed as well. Moreover, the electrochemical impedance spectroscopy of the reference electrode is examined. In the corrosion monitor of reinforced concrete structures, the conclusion gives the baseline to apply the electrode.

Keywords: Corrosion monitoring; Reinforced concrete; Activate carbon; Polarization; Electrochemical impedance spectroscopy

\section{FULL TEXT}

(C) 2016 The Authors. Published by ESG (www.electrochemsci.org). This article is an open access article distributed under the terms and conditions of the Creative Commons Attribution license (http://creativecommons.org/licenses/by/4.0/). 